\title{
Transcraneal Magnetic Stimulation Improves Sleep Parameters in Patients Affected with Imsomnia Associated to Electroencephalographic Abnormalities
}

\author{
Oscar Sánchez-Escandón1, Yoaly Arana-Lechuga², Guadalupe Terán-Pérez², \\ Ángel Ruiz-Chow33, Enrique Esqueda-Leon², Rosa Obdulia González-Robles4, \\ Paul Shkurovich-Bialik' ${ }^{1}$, Miguel Ángel Collado-Corona', Javier Velázquez-Moctezuma ${ }^{2}$ \\ ${ }^{1}$ American British Cowdray Medical Center, Neurological Center, Santa Fe Campus, Ciudad de México, México \\ ${ }^{2}$ Sleep Disorders Clinic, Universidad Autónoma Metropolitana-Iztapalapa, Ciudad de México, México \\ ${ }^{3}$ Psychiatry Department, Hospital General Naval de Alta Especialidad, Ciudad de México, México \\ ${ }^{4}$ Mathematics Department, Universidad Autónoma Metropolitana-Iztapalapa, Ciudad de México, México \\ Email: oscarse@att.net.mx, yoalysoph@hotmail.com, gteran s@hotmail.com, aaruizchow@gmail.com, \\ kike.queda@gmail.com, lugo@xanum.uam.mx, paul.shkurovich@gmail.com, mcollado@prodigy.net.mx, \\ jvm@xanum.uam.mx
}

Received 13 February 2014; revised 5 March 2014; accepted 23 March 2014

Copyright (C) 2014 by authors and Scientific Research Publishing Inc.

This work is licensed under the Creative Commons Attribution International License (CC BY).

http://creativecommons.org/licenses/by/4.0/

(c) (i) Open Access

\begin{abstract}
Insomnia is one of the most frequently observed sleep disorders, affecting nearly $10 \%$ of the general population. It has multiple etiological factors. Recently, it has been reported that EEG abnormalities are associated with insomnia in patients previously diagnosed as idiopathic insomniacs. In addition, transcranial magnetic stimulation (TMS) has shown to be effective in the treatment of disorders characterized by neural hyper-excitability. Method: In the present study, patients with insomnia and EEG abnormalities were submitted to slow repetitive trans-cranial magnetic stimulation, for 15 minutes daily during 10 days. Polysomnographic recordings were performed before and after TMS. Results: The results indicate that the presence of EEG abnormalities significantly decreased after TMS. In addition, most of the sleep parameters showed significant improvement. Conclusions: These data support the notion that TMS is a reliable therapeutic tool for patients affected with abnormalities linked to neuronal hyper-excitability.
\end{abstract}

\section{Keywords}

Insomnia; Transcraneal Magnetic Stimulation; EEG Abnormalities; Hyperexcitability;

How to cite this paper: Sánchez-Escandón, O., Arana-Lechuga, Y., Terán-Pérez, G., Ruiz-Chow, A., Esqueda-Leon, E., GonzálezRobles, R.O., Shkurovich-Bialik, P., Collado-Corona, M.Á. and Velázquez-Moctezuma, J. (2014) Transcraneal Magnetic Stimulation Improves Sleep Parameters in Patients Affected with Imsomnia Associated to Electroencephalographic Abnormalities. Neuroscience \& Medicine, 5, 72-77. http://dx.doi.org/10.4236/nm.2014.51010 


\section{Sleep Architecture; Polysomnographic}

\section{Introduction}

According to the sleep disorders classification, insomnia is characterized by the inability to initiate, maintain or consolidate sleep resulting in an impairment of diurnal performance and decrease quality of life. According to the World Health Organization (WHO), nearly 40\% of the general population complains about insomnia symptomatology for more than two weeks and less than 6 months (acute insomnia), while 10\% of the general population complains of insomnia symptomatology for more than 6 months (chronic insomnia).

Insomnia has multiple subtypes and multiple etiological factors. Regarding idiopathic insomnia, one of the subtypes, we have recently reported that nearly $50 \%$ of the patients diagnosed with this sleep disorder, actually show EEG abnormalities characterized by sharp-wave activity with phase inversion, spikes and sharp-wave activity in the left frontal and front-central area [1].

Furthermore, neuronal hyper-excitability has been reported both in insomniac patients as well as in patients affected with EEG abnormalities. It has been suggested that epileptic-like activity is the result of excessive neuronal excitation as well as impairment of neuronal conductivity inhibition. Epileptic patients resistant to treatment show increased excitability in the motor cortex when compared to epileptic patients that respond adequately to treatment [2]. On the other hand, EEG recordings obtained from insomniac patients show an increase of beta and gamma activity during sleep onset and light sleep, suggesting neuronal hyper-excitability [3]. Moreover, using a Positron Emission Tomography (PET), Noftzinger reported an increase of global glucose consumption in insomniac patients during wake-sleep transition [4].

On the other hand, Transcranial Magnetic Stimulation (TMS) is a new tool for noninvasive stimulation of the nervous system. In 1985, Barker et al. reported the use of TMS in the motor pathways using a single stimulus. However, it was introduced as a therapeutic tool only when TMS was able to deliver repetitive stimuli in 1993 by Houser et al.

Currently, TMS has been proposed as a therapeutic tool for several illnesses of the nervous system, such as depression [5] and others characterized mainly by neuronal hyper-excitabilit [6], such as post-traumatic stress disorder [7], obsessive compulsive disorder and schizophrenia, among others [8]. Previous reports have shown that TMS has therapeutic effects on insomnia in patients affected with post-traumatic stress disorders. Most patients reported a subjective improvement in sleep quality after a 10-day TMS treatment [9].

In the present study, TMS was applied to patients diagnosed with insomnia associated to EEG abnormalities.

\section{Methods}

Ten adult patients (4 males: 6 females; age range 19 - 35) were included in this study. All patients were diagnosed initially with idiopathic insomnia, and the presence of abnormal electroencephalographic activity during sleep was detected.

All patients attended two polysomnographic recordings (PSGR), one before and one after TMS therapy. This study included recording electroencephalographic (EEG), electrooculography (EOG), electromyography (EMG) and electrocardiographic (EKG) activities, as well as respiratory variables (thoracic-abdominal exertion, nasal flow and oximetry). To record cortical activity, a conventional electroencephalographic set up, including 16 channels with bi-polar leads, was used. The sleep recordings were made at the Universidad Autónoma Metropolitana Sleep Disorders Clinic with a 32 channel Caldwell digital polygraph. Sleep recording interpretation was based on the Rechtschaffen and Kales manual [9] and its adequacies published in 2007 by the American Academy of Sleep Medicine [10]. All patients signed informed consent forms to participate in the study and their agreement to delay any kind of treatment or therapy to control their sleep disorder during TMS therapy. After the initial PSG recording, patients were submitted daily to 15 minutes (900 pulses) of slow (1 HZ) TMS for 10 days. TMS was delivered using a Magstim 2004 with an 8-shape stimulator. TMS was applied over the skull in the region were the EEG abnormalities were found (left frontal and front-central areas). Once TMS ended, a second PSG recording was done using the same montage as described above.

Results were analyzed using a student $\mathrm{T}$ test (before and after therapy) as well as a Chi square test for analysis of proportions. 
This study was evaluated and approved by the bioethics committee of the ABC Medical Center.

\section{Results}

TMS induced significant improvement in most sleep parameters, especially in those affected in insomnia patients. Table 1 shows the sepolysomnographic parameters. As can be observed, sleep efficiency increased significantly, as well as total sleep time. In addition, sleep latency decreased, as well as total wake time (Figure 1). The arousal index and awakenings showed a nonsignificant decrease.

Table 1. Polysomnographic parameters.

\begin{tabular}{|c|c|c|c|}
\hline & Before treatment & After Treatment & sig. $\mathbf{p}<0.05$ \\
\hline SL min $( \pm$ SEM) & $46 \pm(19.3)$ & $17.3 \pm(6.5)$ & 0.025 \\
\hline TST min $( \pm$ SEM) & $328 \pm(52.6)$ & $417.3 \pm(22.9)$ & 0.011 \\
\hline TWT \% ( \pm SEM $)$ & $150.5 \pm(52.1)$ & $54.5 \pm(23)$ & 0.004 \\
\hline WASO min $( \pm$ SEM $)$ & $104.4 \pm(43.6)$ & $37.2 \pm(22)$ & 0.005 \\
\hline REML min $( \pm$ SEM) & $154.8 \pm(41)$ & $96.9 \pm(15.2)$ & \\
\hline LS \% ( \pm SEM) & $65.4 \pm(7)$ & $59.4 \pm(5.5)$ & \\
\hline SWS \% ( \pm SEM) & $20 \pm(7.8)$ & $19.1 \pm(4)$ & \\
\hline REM \% ( \pm SEM) & $20.2 \pm(8.6)$ & $21.4 \pm(2.1)$ & \\
\hline Num of awakenings $( \pm$ SEM) & $14.4 \pm(3.5)$ & $11.7 \pm(2.4)$ & \\
\hline Arousal index $( \pm$ SEM) & $6.8 \pm(2.5)$ & $5.6 \pm(1.4)$ & \\
\hline SE $( \pm$ SEM) & $68.3 \pm(10.9)$ & $88.3 \pm(4.7)$ & 0.004 \\
\hline EEG abnormalities index ( \pm SEM) & $21.2(10.3)$ & $7.1(1.6)$ & 0.037 \\
\hline
\end{tabular}

Table 1 shows the mean and standard error $( \pm$ SEM) of polysomnographic variables and electroencephalographic abnormalities in insomnia patient before and after treatment. (SL: Sleep Latency, TST: Total Sleep Time, TWT: Total Wake Time, WASO: Wake time After Sleep Onset, REML: Rapid Eyes Movement Sleep Latency, LS: Light Sleep, SWS: Slow Wave Sleep, REM: Rapid Ayes Movement Sleep, SE: Sleep Efficiency).

\section{Sleep Parameters}
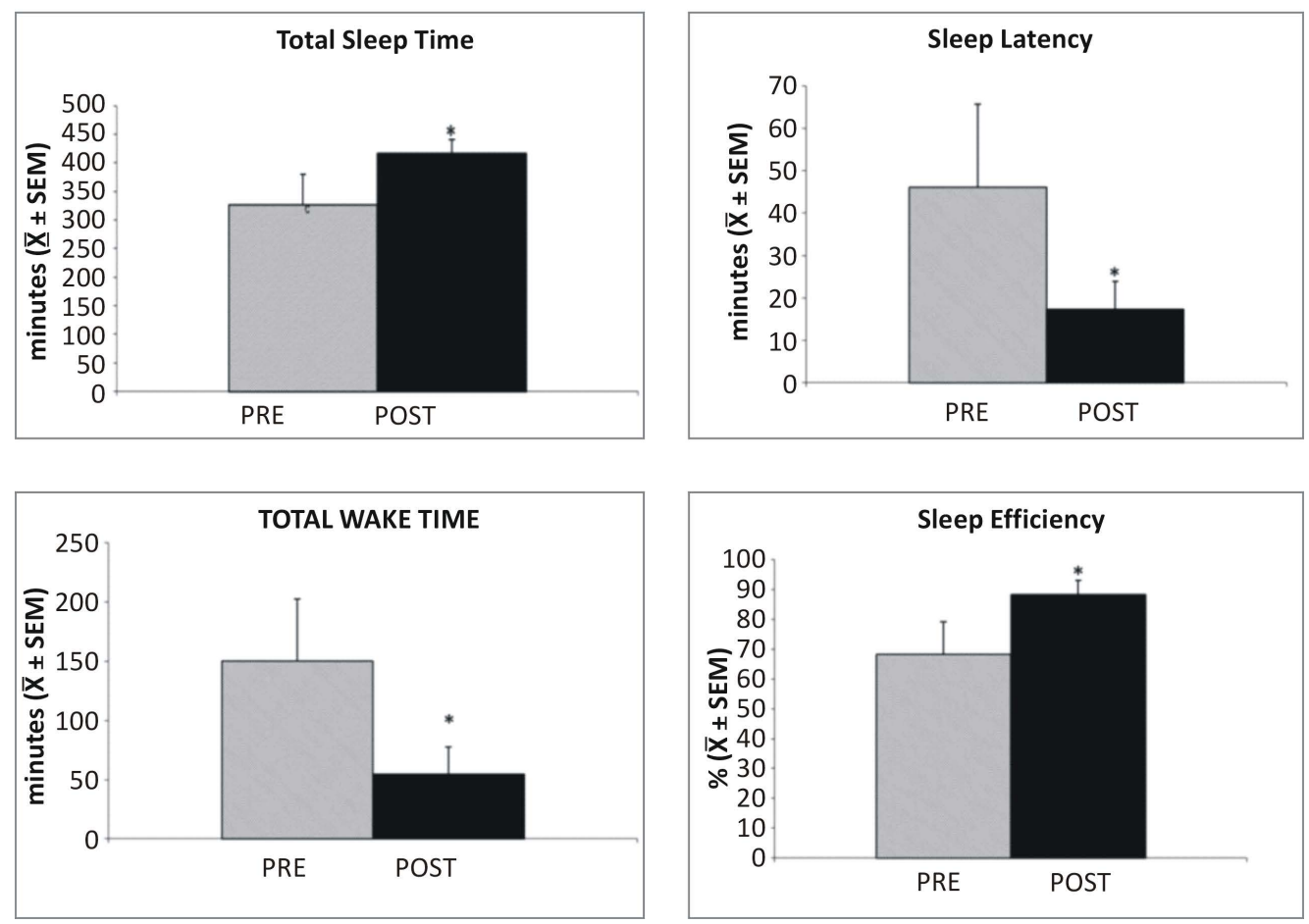

Figure 1. Shows total sleep time, sleep latency, total wake time and sleep efficiency, before and after TMS therapy. All these variables showed significant differences $(\mathrm{p}<0.05$ student $\mathrm{T}$ test $)$. 
As mentioned before, all patients studied displayed EEG abnormalities in the initial EEG recording. After TMS, the frequency of EEG abnormalities decreased significantly (Figure 2).

Regarding sleep architecture, no significant differences were found after TMS in the percentage of light sleep, slow wave sleep and REM sleep (Figure 3).

Finally, REM sleep latency, which initially showed an abnormal increase, returned to the normally reported values after TMS treatment. However, this difference was not statistically significant (Figure 4).

EEG Abnormalities

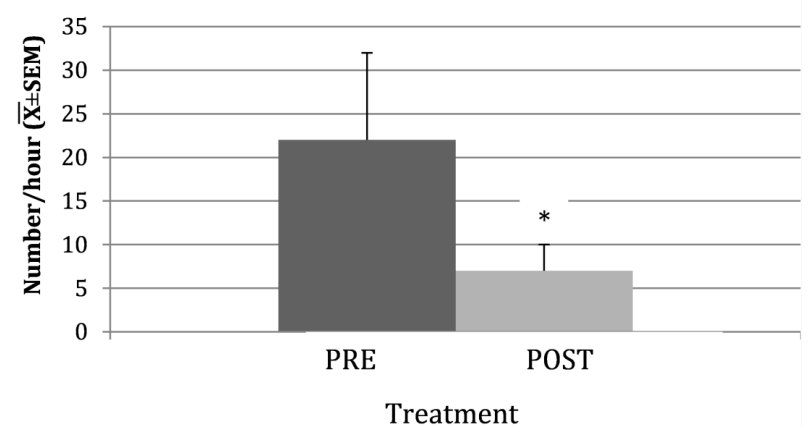

Figure 2. Shows the electroencephalographic abnormalities index pre and post TMS ${ }^{*} \mathrm{p}<0.05$ student $\mathrm{T}$ test $)$.

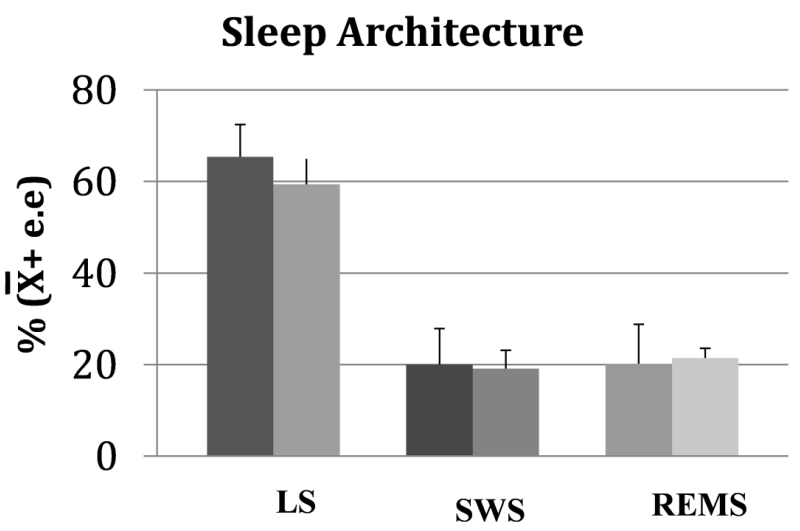

Figure 3. Shows the percentage of all sleep stages before and after therapy. No significant differences were found.

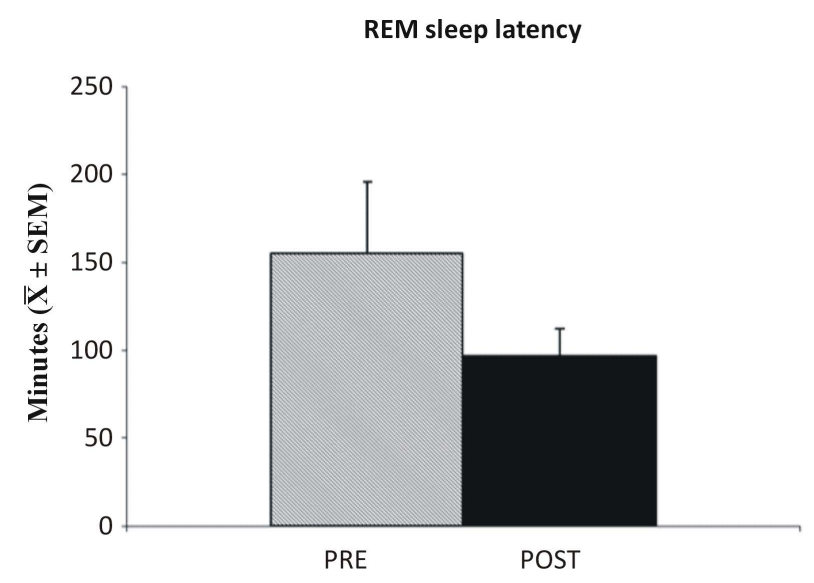

Figure 4. Shows REM sleep latency before and after therapy. No significant differences were found. 


\section{Discussion}

The results consistently showed that daily, 15 minutes of TMS applied for 10 days, improve sleep parameters in patients affected with insomnia associated to EEG abnormalities. Recently, our group reported that nearly 50\% of patients diagnosed with idiopathic insomnia actually show EEG abnormalities. This study also described a clear association between EEG abnormality frequency and the severity of insomnia [1].

In the present study, the improvement of sleep parameters coincides with a significant decrease of EEG abnormalities, suggesting that the effect of TMS on sleep is due to the inhibition of EEG abnormalities.

Regarding the findings in the PSG recording, it is important to highlight the fact that the increase of total sleep time is not due to the increase of only one sleep stage. All stages of sleep-light sleep, slow wave sleep and REM sleep-showed a proportional increase. This is a crucial difference with the current pharmacological treatment of insomnia. Most of these drugs increase total sleep time by increasing light sleep, resulting in low sleep quality, as well as in an increase in diurnal somnolence [11] [12]. Furthermore, TMS induced a normalization of REM sleep latency (mean $96 \mathrm{~min}$ ) for this age group [13].

TMS is a tool, the therapeutic applications of which are rapidly spreading [14]-[19]. TMS allows stimulation of the central nervous system in a harmless way, without the use of electrodes or any other device. TMS can be slow $(<1 \mathrm{~Hz})$ or fast $(>5 \mathrm{~Hz})$. Slow TMS has a suppressor effect while fast TMS induces activation [18]. Slow, repetitive TMS has been successfully used in neuropsychiatric diseases linked to neuronal hyper-excitability, such as obsessive compulsive disorder, post-traumatic stress disorder, schizophrenia, Tourette's syndrome, and multiple sclerosis, among others [20]-[22]. Insomnia, the presence of EEG abnormalities, has been reported as a neuronal hyper-excitability disease [23]-[25].

Our results regarding TMS and sleep are consistent with those reported by Rosenberg et al., in patients suffering from insomnia associated to post-traumatic stress disorder [11].

Whether TMS improves insomnia symptoms or causes the decrease of EEG abnormalities making better sleep, is a question that must be answered by new researchers. A positive relation between the severity of insomnia and the frequency of EEG abnormalities has previously been reported [1].

\section{References}

[1] Arana, L., Sánchez, E., Collado, C., Castillo, M., González, R., Jiménez, A., Prospero, G. and Velázquez, M. (2011) Electroencephalographic Abnormalities in Patients with Idiopathic Insomnia. Neuroscience \& Medicine, 2, 178-184. http://dx.doi.org/10.4236/nm.2011.23024

[2] Cantello, R., Civardi, C., Cavalli, A., Varrasi, C., Tarletti, R., Monaco, F. and Migliaretti, G. (2000) Cortical Excitability in Cryptogenic Localization-Related Epilepsy: Interictaltranscranial Magnetic Stimulation Studies. Epilepsia, 41, 694-704. http://dx.doi.org/10.1111/j.1528-1157.2000.tb00230.x

[3] Perlis, M.L., Merica, H., Smith, M.T. and Giles, D.E. (2001) Beta EEG Activity and Insomnia. Sleep Medicine Reviews, 5, 365-376. http://dx.doi.org/10.1053/smrv.2001.0151

[4] Nofzinger, E.A., Buysse, D.J., Germain, A., et al. (2004) Functional Neuroimaging Evidence for Hyperarousal in Insomnia. American Journal of Psychiatry, 161, 2126-2128. http://dx.doi.org/10.1176/appi.ajp.161.11.2126

[5] Berman, R.M., Narasimhan, M., Sanacora, G., Miano, A.P., Hoffman, R.E., Hu, S., Charney, D.S. and Boutros, N.N. (2000) A Randomized Clinical Trial of Repetitive Transcranial Magnetic Stimulation in the Treatment of Major Depression. Biological Psychiatry, 47, 332-337. http://dx.doi.org/10.1016/S0006-3223(99)00243-7

[6] Hoffman, R. and Cavus, I. (2002) Slow Transcranial Magnetic Stimulation, Long-Term Depotentiation, and Brain Hyperexcitability Disorders. American Journal of Psychiatry, 159, 1093-1102.

http://dx.doi.org/10.1176/appi.ajp.159.7.1093

[7] Grisaru, N., Amir, M., Cohen, H. and Kaplan, Z. (1998) Effect of Transcranial Magnetic Stimulation in Posttraumatic Stress Disorder: A Preliminary Study. Biological Psychiatry, 44, 53-55. http://dx.doi.org/10.1016/S0006-3223(98)00016-X

[8] Haraldsson, H.M., Ferrarelli, F., et al. (2004) Transcranial Magnetic Stimulation in the Investigation and Treatment of Schizophrenia: A Review. Schizophrenia Research, 71, 1-16. http://dx.doi.org/10.1016/j.schres.2003.10.006

[9] Rechtschaffen, A. and Kales, A. (1968) A Manual of Standardized Terminology: Techniques and Scoring System of Sleep Stages of Human Subjects. UCLA Brain Information Service/Brain Research Institute, Los Angeles.

[10] The American Academy of Sleep Medicine (2007) Rules, Terminology and Technical Specifications. The American Academy of Sleep Medicine, Westchester.

[11] Rosenberg, P.B., Mehndiratta, R.B., Mehndiratta, Y.P., Wamer, A., Rosse, R.B. and Balish, M. (2002) Repetitive 
Transcranial Magnetic Stimulation Treatment of Comorbid Posttraumatic Stress Disorder and Major Depression. Journal of Neuropsychiatry and Clinical Neurosciences, 14, 270-276. http://dx.doi.org/10.1176/appi.neuropsych.14.3.270

[12] Lieberman, J.A. (2007) Update on the Safety Considerations in the Management of Insomnia with Hypnotics: Incorporating Modified-Release Formulations into Primary Care. Primary Care Companion to the Journal of Clinical Psychiatry, 9, 25-31. http://dx.doi.org/10.4088/PCC.v09n0105

[13] Thorpy, M.J. and Yager, J. (1991) The Encyclopedia of Sleep and Sleep Disorders. Facts on File Inc., New York.

[14] D’Alfonso, A.A.L., van Honk, J., Hermans, E., Postma, A. and de Haan, E.H.F. (2000) Laterality Effects in Selective Attention to Threat after Repetitive Transcranial Stimulation at the Prefrontal Cortex in Female Subjects. Neuroscience Letters, 280, 195-198. http://dx.doi.org/10.1016/S0304-3940(00)00781-3

[15] George, M.S., Wassermann, E.M. and Post, R.M. (1996) Transcranial Magnetic Stimulation: A Neuropsychiatric Tool for the 21st Century. Journal of Neuropsychiatry and Clinical Neurosciences, 8, 373-382.

[16] George, M.S., Lisanby, S.H. and Sackeim, H.A. (1999) Transcranial Magnetic Stimulation: Applications in Neuropsychiatry. Archives of General Psychiatry, 56, 300-311. http://dx.doi.org/10.1001/archpsyc.56.4.300

[17] Lennox, B.R., Park, S.B., Medley, I., Morris, P.G. and Jones, P.B. (2000) The Functional Anatomy of Auditory Hallucinations in Schizophrenia. Psychiatry Research, 100, 13-20. http://dx.doi.org/10.1016/S0925-4927(00)00068-8

[18] Post, R.M., Kimbrell, T.A., Frye, M., George, M., McCann, U., Little, J., Dunn, R., Li, H. and Weiss, S.R.B. (1997) Implications of Kindling and Quenching for the Possible Frequency Dependence of rTMS. CNS Spectrums, 2, 54-60.

[19] Speer, A.M., Kimbrell, T.A., Wassermann, E.M., Repella, J.D., Willis, M.W., Herscovitch, P. and Post, R.M. (2000) Opposite Effects of High and Low Frequency rTMS on Regional Brain Activity in Depressed Patients. Biological Psychiatry, 48, 1133-1141. http://dx.doi.org/10.1016/S0006-3223(00)01065-9

[20] McCann, U.D., Kimbrell, T.A., Morgan, C.M., Geraci, M., Benson, B.E., Wassermann, E.M., Willis, M.W. and Post, R.M. (1998) Repetitive Transcranial Magnetic Stimulation for Posttraumatic Stress Disorder (Letter). Archives of General Psychiatry, 55, 277-279. http://dx.doi.org/10.1001/archpsyc.55.3.276

[21] Alonso, P., Pujol, J., Cardoner, N., Benlloch, L., Deus, J., Menchón, J.M., Capdevila, A. and Vallejo, J. (2001) Right Prefrontal Repetitive Transcranial Magnetic Stimulation in Obsessive-Compulsive Disorder: A Double-Blind, Placebo-Controlled Study. American Journal of Psychiatry, 158, 1143-1145. http://dx.doi.org/10.1176/appi.ajp.158.7.1143

[22] Haraldsson, H.M., Ferrarelli, F., et al. (2004) Transcranial Magnetic Stimulation in the Investigation and Treatment of Schizophrenia: A Review. Schizophrenia Research, 71, 1-16. http://dx.doi.org/10.1016/j.schres.2003.10.006

[23] Nofzinger, E.A., Buysse, D.J., Germain, A., et al. (2004) Functional Neuroimaging Evidence for Hyperarousal in Insomnia. American Journal of Psychiatry, 161, 2126. http://dx.doi.org/10.1176/appi.ajp.161.11.2126

[24] Post, R.M. and Weiss, S.R. (1997) Emergent Properties of Neural Systems: How Focal Molecular Neurobiological Alterations Can Affect Behavior. Development and Psychopathology, 9, 907-929. http://dx.doi.org/10.1017/S0954579497001491

[25] Tassinari, C.A., Cincotta, M., Zaccara, G. and Michelucci, R. (2003) Transcranial Magnetic Stimulation and Epilepsy. Clinical Neurophysiology, 114, 777-798. http://dx.doi.org/10.1016/S1388-2457(03)00004-X 